\title{
90. The Synthesis of Gadolinite
}

\author{
By Jun Iто \\ Mineralogical Institute, University of Tokyo*) \\ (Comm. by Tei-ichi Ito, M.J.A., May 19, 1965)
}

Minerals of the gadolinite type have been synthesized hydrothermally and also under the air pressure by heating certain mixtures previously treated chemically as well as physically. We assume hereby that the material after treatment, which is used as the starting gel of synthesis, is pure in composition and is in a state easily convertible into the crystalline state. The typical procedure of experiment follows: $2 \mathrm{mM}$ of respective rare earth oxides and $1 \mathrm{mM}$ of the corresponding divalent soluble salts or oxides are dissolved into $100 \mathrm{ml}$ of $0.4 \mathrm{~N}$ of hydrochloric solution containing $\mathrm{BeCl}_{2}$ and $\mathrm{Na}_{2} \mathrm{SiO}_{3}$. Some rare earth does not dissolve readily into solution and heating is needed. Care must be taken to prevent oxidation of ferrous ions. When dissolution is completed $2 \mathrm{M} \mathrm{NaOH}$ solution is added to make the solution neutral. While the solution is sterred on a magnetic stirrer precipitation is performed. The precipitates, a mixture of hydrous silicates and hydro-oxides having the composition aimed at, are washed by cold distilled water and by methyl alcohol by means of a centrifuge. The excess $\mathrm{NaOH}$ and $\mathrm{NaCl}$ which remain still in the precipitates are washed off again. Washing and the ensuing drying in vacuum with slight heating are repeated several times if necessary. The final preparates ready for synthesis contain about $50 \%$ by weight of water and alcohol.

The experiment has furnished us with a considerable number of compounds of the gadolinite $\left(\mathrm{FeY}_{2} \mathrm{Be}_{2} \mathrm{Si}_{2} \mathrm{O}_{10}\right)$ and hydrogadolinite $\left(\mathrm{H}_{2} \mathrm{Y}_{2} \mathrm{Be}_{2} \mathrm{Si}_{2} \mathrm{O}_{10}\right)$ type, obtained by replacing isomorphously $\mathrm{Fe}$ by $\mathrm{Mg}, \mathrm{Ni}$, $\mathrm{Co}, \mathrm{Zn}, \mathrm{Cu}, \mathrm{Mn}$, and $\mathrm{Cd}$ on one hand and by replacing $\mathrm{Y}$ by $\mathrm{La}, \mathrm{Ce}$, $\mathrm{Nd}, \mathrm{Sm}, \mathrm{Gd}, \mathrm{Dy}, \mathrm{Er}, \mathrm{Tm}, \mathrm{Yb}$, and Lu on the other. The series of artificial minerals produced, some of which exhibit definite crystalforms under the microscope (Fig. 1), were examined crystallographically by means of an X-ray diffractometer (Fig. 2), their X-ray diagrams having been indexed on the basis of the crystal structure as worked out by Ito and Mori. ${ }^{1)}$ The lattice constants of a selection of the compounds are given in Table I.

*) The present address: Department of Geological Sciences, Harvard University, Cambridge, Mass., U.S.A.

1) Ito, T., and Mori, H.: Acta Crystallographica, 6, 31 (1952). 
The result will demonstrate the effect of ionic size on the lattice of the respective crystals formed. One of the most interesting crystallochemical findings is the behavior of the lattice constants, the $\beta$-angles in particular (Fig. 3) which are dependent in a characteristic way on the variation of size of the component ions. It seems further

a)
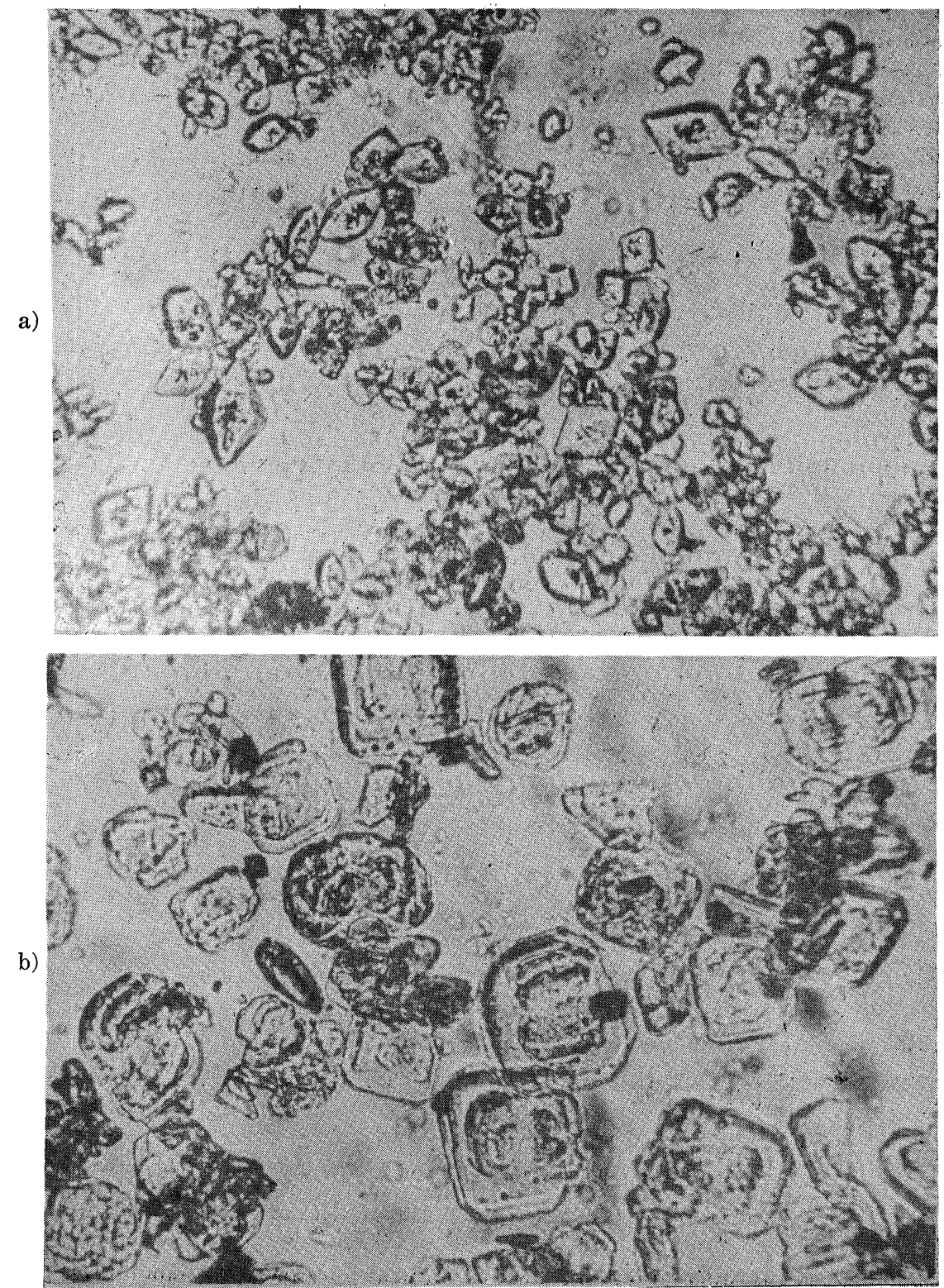

Fig. 1. Photomicrographs of artificial gadolinites.
a) $\mathrm{FeDy}_{2} \mathrm{Be}_{2} \mathrm{Si}_{2} \mathrm{O}_{10}$.
$700^{\circ} \mathrm{C}, 32,000 \mathrm{psi}, 48 \mathrm{hrs} . \quad \times 200$
b). $(\mathrm{HMn}) \mathrm{Ce}_{2} \mathrm{Be}_{2} \mathrm{Si}_{2} \mathrm{O}_{10}$.
$600^{\circ} \mathrm{C}, 28,000 \mathrm{psi}, 20 \mathrm{hrs} . \quad \times 200$ 
Table I. Lattice constants of gadolinite and artificial minerals of the same type

\begin{tabular}{lccrll}
\hline & $\mathrm{a}$ & $\mathrm{b}$ & $\mathrm{c}$ & $\beta$ & \\
\hline Gadolinite from Otomé, & $4.71 \mathrm{~A}$ & $7.52 \mathrm{~A}$ & $9.89 \mathrm{~A}$ & $90^{\circ} 32^{\prime}$ & (morphological) \\
Japan (Ito \& Mori) & & & & & \\
$\mathrm{FeY}_{2} \mathrm{Be}_{2} \mathrm{Si}_{2} \mathrm{O}_{10}$ & 4.72 & 7.51 & 9.90 & $90^{\circ} .3$ & \\
$\mathrm{MnLa}_{2} \mathrm{Be}_{2} \mathrm{Si}_{2} \mathrm{O}_{10}$ & 4.88 & 7.78 & 10.28 & 91.0 & \\
$\mathrm{CuSm}_{2} \mathrm{Be}_{2} \mathrm{Si}_{2} \mathrm{O}_{10}$ & 4.77 & 7.62 & 10.00 & 90.0 & \\
$\mathrm{ZnYb}_{2} \mathrm{Be}_{2} \mathrm{Si}_{2} \mathrm{O}_{10}$ & 4.70 & 7.43 & 9.90 & 90.6 & \\
$\mathrm{MgCe}_{2} \mathrm{Be}_{2} \mathrm{Si}_{2} \mathrm{O}_{10}$ & 4.79 & 7.69 & 10.18 & 91.4 & \\
$\mathrm{NiNd}_{2} \mathrm{Be}_{2} \mathrm{Si}_{2} \mathrm{O}_{10}$ & 4.77 & 7.62 & 10.09 & 90.9 & \\
$\mathrm{CoDy}_{2} \mathrm{Be}_{2} \mathrm{Si}_{2} \mathrm{O}_{10}$ & 4.73 & 7.49 & 9.96 & 90.0 & \\
$\mathrm{CdGd}_{2} \mathrm{Be}_{2} \mathrm{Si}_{2} \mathrm{O}_{10}$ & 4.82 & 7.58 & 10.12 & 90.6 & \\
$\mathrm{H}_{2} \mathrm{Y}_{2} \mathrm{Be}_{2} \mathrm{Si}_{2} \mathrm{O}_{10}$ & 4.74 & 7.61 & 9.88 & 90.1 & \\
$\mathrm{H}_{2} \mathrm{Tm}_{2} \mathrm{Be}_{2} \mathrm{Si}_{2} \mathrm{O}_{10}$ & 4.71 & 7.57 & 9.90 & 90.8 \\
$\mathrm{H}_{2} \mathrm{Er}_{2} \mathrm{Be}_{2} \mathrm{Si}_{2} \mathrm{O}_{10}$ & 4.74 & 7.59 & 9.90 & 90.6 & \\
\hline
\end{tabular}

(a)

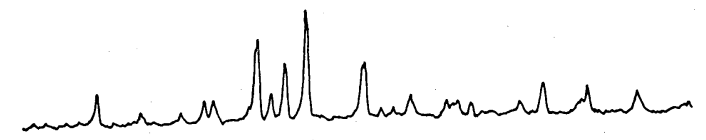

(b)

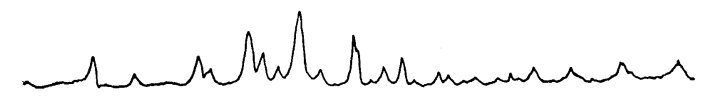

(c)

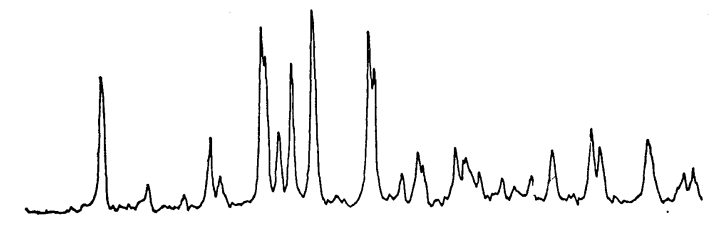

(d)

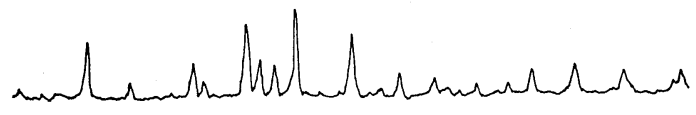

(e)

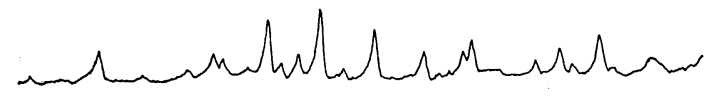

( f)

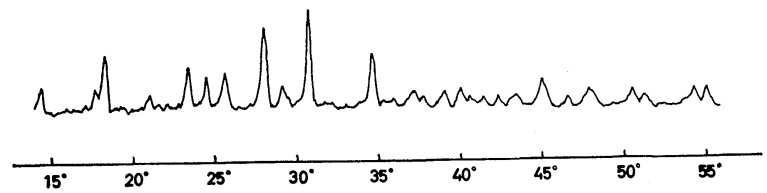

Fig. 2. X-ray diffraction diagrams of natural and artificial gadolinites.
a) Natural
d) $\mathrm{ZnSm}_{2} \mathrm{Be}_{2} \mathrm{Si}_{2} \mathrm{O}_{10}$
b) $\mathrm{MnNd}_{2} \mathrm{Be}_{2} \mathrm{Si}_{2} \mathrm{O}_{10}$
e) $\mathrm{MgY}_{2} \mathrm{Be}_{2} \mathrm{Si}_{2} \mathrm{O}_{10}$
c) $\mathrm{CuY}_{2} \mathrm{Be}_{2} \mathrm{Si}_{2} \mathrm{O}_{10}$
f) $\mathrm{H}_{2} \mathrm{Nd}_{2} \mathrm{Be}_{2} \mathrm{Si}_{2} \mathrm{O}_{10}$ 


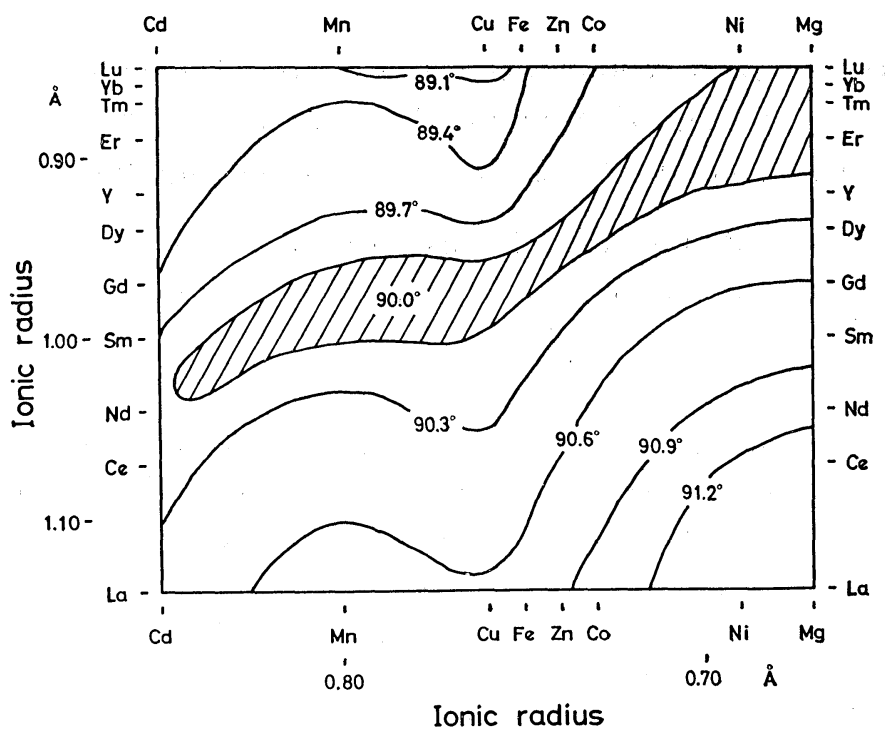

Fig. 3. Variation of the $\beta$-angles of artificial gadolinite.

to suggest that a correction should be made in the usually assumed values of size of certain ions.

The present study has been undertaken originally to establish, if possible, the stability relation of minerals of the gadolinite type. In view of the fact that gadolinites are synthesized not only hydrothermally at a relatively low temperature, $300^{\circ} \mathrm{C}$, but also by heating at a little elevated temperature, $700^{\circ} \mathrm{C}$, under the atmospheric condition they are probably stable in a very wide range of PT, say, the temperature from $300^{\circ}$ to $1200^{\circ}$ and the pressure from one to several thousand atmosphers. As to the $\mathrm{Zn}-\mathrm{Y}$ gadolinite, whose formation was closely observed, the following remarks may be worth noting here. The content of $\mathrm{Y}$ and $\mathrm{Si}$ has a marked effect on the persistance of the gadolinite structure, while that of $\mathrm{Be}$ and $\mathrm{Zn}$ has therewith little to do. The detail of the study will be published later eleswhere. 